\title{
Optimization of Secondary Cooling Water Distribution for Billet Continuous Casting Based on Neural Network
}

\author{
Zhao Lirui ${ }^{1, a,}{ }^{*}$, Han Wei ${ }^{2, b}$, Zhang Jinhong ${ }^{1, c}$ \\ ${ }^{1}$ Information Engineering and Automation Department, Hebei College of Industry and Technology, \\ Shijiazhuang, 050091, Hebei, China \\ ${ }^{2}$ HBIS Group Shisteel Company, Shijiazhuang, 050091, Hebei, China \\ aemail:Zhaolirui@163.com, ${ }^{\text {bemail:17485778@qq.com, }{ }^{\mathrm{c} e m a i l}: 34422508 @ q q . c o m, ~}{ }^{*}$ corresponding \\ author
}

Keywords: Self-adaption; Mathematical model of solidification and heat transfer; Neural network; Secondary cooling water distribution model; Optimization; Control

\begin{abstract}
In order to make the secondary cooling of continuous casting have the adaptive ability to adapt to the changes of process parameters in the production process, it's based on the mathematical model of solidification and heat transfer of continuous casting billet, combined with casting speed, super heat and the type of steel, the secondary cooling water distribution model is established. Furthermore, the slab cooling adaptive control system is establish based on neural network, it realize the adaptive of water distribution, and gives the design scheme of the secondary cooling water system for continuous casting. To do the site test based on the selection of $360 * 360 \mathrm{~mm}$ billet of a steel production section, and the verification results show that the solidification heat transfer mathematics model can better simulate the solidification process and predict the change of the surface temperature of the slab. The slab cooling adaptive control system based on neural network can respond to the site process parameters well and give the effective control of the optimization of the secondary cooling water.
\end{abstract}

\section{Introduction}

The secondary cooling of slab is the key link in continuous casting, and it has a great impact on the quality of the slab. It is shown that the surface temperature of the billet will be not controlled to the target value if the secondary cooling is unsuitable. As a result, it will cause billet surface cracks, center porosity, center segregation and some other quality defects, and finally reduce the casting production [1]. In order to improve the casting yield and reduce the quality defects of casting billet. It is necessary to study a reasonable and effective secondary cooling control strategy according to different steel grades and process conditions.

At present, the cooling water of the secondary cooling control system is still calculated according to the casting speed and simple heat transfer model, but the continuous casting process of casting billet is a complex non-linear time-varying system, it is difficult to estimate the parameters by using the above control method, so the results are not accurate. The neural network can approach to any nonlinear function, so it does not need any restrictions on the nonlinear structure of the system, so it provides a powerful tool for nonlinear control [2]. Therefore, based on the neural network, we can select a suitable secondary cooling water distribution control model, establishing the reasonable and effective secondary cooling control system is very important.

\section{Establishment of Slab Cooling Process Model}

Mathematical Model of Solidification and Heat Transfer. Continuous casting is essentially a cooling process. In the whole process, not only the molten steel overheating and melting heat is released, but also the excess heat after solidification is emitted out. Therefore, it is very important to establish accurate mathematical model of solidification process to achieve predictable cooling control and improve the quality of casting billet. 
The assumptions of solidification heat transfer mathematical model of billet are as follows [3]: (1)Only considering the heat transfer in thickness of slab, while the heat transfer in width and casting direction were ignored. (2)The temperature of casting billet along with the casting direction is in a non-steady state. (3)The density and hot melt of the steel were equivalent to constant, and were fixed invariant. (4)The liquid temperature and solid phase temperature were fixed invariant. (5)The billet is considered to be uniformly cooled in the same cooling zone of the two cooling zone. (6)The contact heat transfer between the two cooling zone and the slab and the radiation heat transfer of the slab are neglected.

Based on the above assumptions, combined with the casting billet and its cooling symmetry, the partial different equation of solidification heat transfer of the billet is established. 1/4 section is considered as the research object.

$$
\rho C \frac{\partial T}{\partial t}=\frac{\partial}{\partial x}\left(\lambda \frac{\partial T}{\partial x}\right)+\frac{\partial}{\partial y}\left(\lambda \frac{\partial T}{\partial y}\right)
$$

Where the $\rho$ is the steel density; $C$ is specific heat capacity; $T$ is temperature; $x$ is width direction of the casting billet; $y$ is the thickness direction of casting billet; $t$ is time.

To solve the partial different equation, the following boundary conditions[4]:

(1) Heat flux in the crystalline region:

(2) Heat flux of air cooling zone:

$$
q_{\mathrm{s}}=A-B \sqrt{t}
$$

(3)Heat flux of two cooling zone:

$$
s=\varepsilon \rho\left[\left(T_{\mathrm{b}}+273\right)^{4}-\left(T_{\mathrm{o}}+273\right)^{4}\right]
$$

$$
q_{\mathrm{s}}=h\left(T_{\mathrm{b}}-T_{\mathrm{w}}\right)
$$

Where the $T_{\mathrm{b}}, T_{\mathrm{o}}, T_{\mathrm{w}}$ expressed the surface temperature of casting billet, ambient temperature and cooling water temperature, respectively; $q_{\mathrm{s}}$ is surface heat flux; $\varepsilon$ is blackness, the value of blackness is 0.7-0.8; $\sigma$ is the Boltzmann constant, the value of $\sigma$ is $5.675 \times 10^{8} \mathrm{~W} /\left(\mathrm{m}^{2} \cdot \mathrm{k}^{4}\right)$; $h$ is heat transfer coefficient. Combined with the actual situation, the $h$ can be described as follows:

$$
h=82 W^{0.75} V_{S}^{0.4}
$$

Where the $W$ is the water flow density; $V_{\mathrm{S}}$ expressed spray water droplet velocity.

The mathematical model of solidification and heat transfer are constituted by all the above boundary conditions and formula(1). The surface temperature distribution of casting billet during solidification can be predicted accurately by solving the formula (1) with boundary conditions.

The Mathematical Model of Secondary Cooling Water Distribution. In order to ensure that molten steel can flow well into the crystallizer, the temperature of liquid steel in bakie must be high enough in the continuous casting production. However, if the liquid steel temperature is too high, it would lead to mass defects such as center segregation. Therefore, the bakie liquid steel temperature is the key factor to control the cooling degree and quality of continuous casting billet. During the secondary cooling, it is necessary to consider not only the influence of casting speed and steel, but also the influence of the teeming temperature. Combined with the influence of casting speed and teeming temperature, the mathematical model of secondary cooling water distribution is established as follow:

$$
Q_{i}=A_{i} V^{2}+B_{i} V+C_{i}+D T_{i}
$$

Where the $Q_{\mathrm{i}}$ is the cooling water in two cooling zone $i$; $V$ is the casting speed; $T_{\mathrm{i}}$ is the teeming temperature; $A_{\mathrm{i}}, B_{\mathrm{i}}, C_{\mathrm{i}}, D_{\mathrm{i}}$ are control parameters, which is decided by casting speed, steel billet, the section size of casting billet and the temperature of liquid steel.

\section{Neural Network Control of Billet Cooling Temperature}

Because the process of continuous casting is very complicated and the cooling process of continuous casting billet is a nonlinear time-varying system, and neural networks can approach to any nonlinear function, the neural network can be used to control and forecast the cooling temperature of continuous casting billet[5]. Therefore, a billet cooling adaptive controller is proposed base on the neural network, it need not computing the inverse matrix and thus reduces 
computation quantity greatly. The structure chart of neural network is shown in Fig.1.

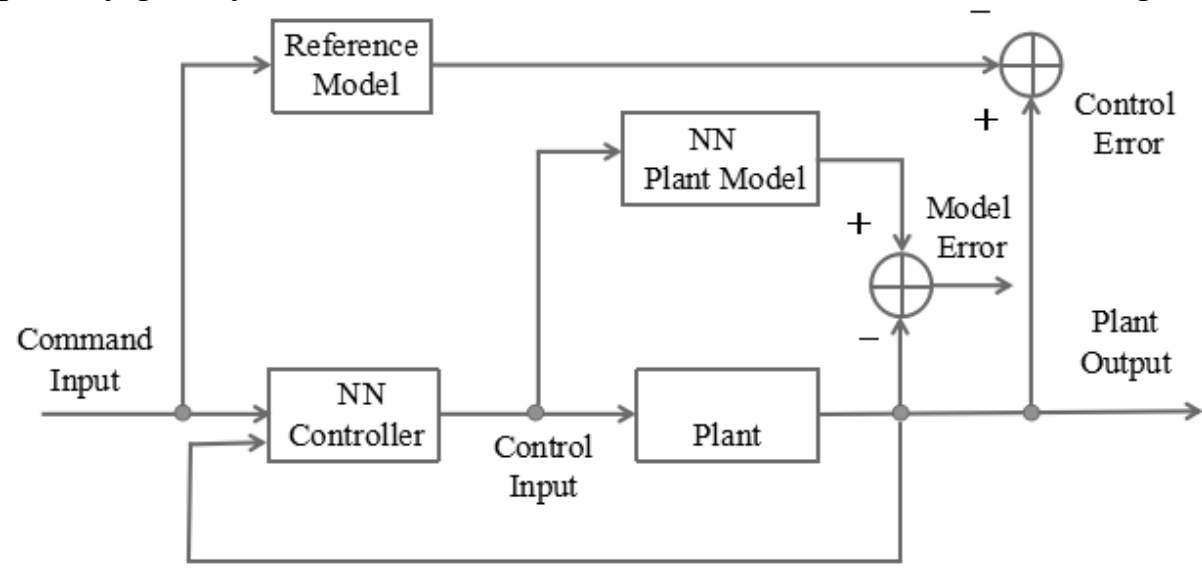

Fig.1 Structure chart of neural network

The process of solidification of casting billet can be described by using a nonlinear system.

$$
\begin{aligned}
& y(k)=a_{1} y(k-1)+\ldots+a_{n} y(k-n)+f[u(k-d), u(k-d-1), \ldots, \\
& u(k-d-m+1)]+e(k)
\end{aligned}
$$

Where the $y(\mathrm{k})$ is the surface temperature of the casting billet at a measuring point; $u(\mathrm{k})$ is the cooling water for this measuring section; $f(\cdot)$ is a smooth nonlinear function with unknown structure; Parameter $m, n$ were identified by identification experiment; $d$ is system delay of casting billet cooling system which can be get from temperature response; $e(k)$ is white noise disturbance, which the mean value is zero and the variance is $\lambda^{2}$.

To solve the control law by using the equation 7 is too complex. In order to calculate conveniently, the Taylor's theorem is used to approximate the formula 7. The model of billet cooling control system was obtained as follow:

$$
y(k+d)=A z^{-1} y(k)+f[u(k), u(k-1), \cdots, u(k-m+1)]
$$

Where

$$
W=[u(k-1), \cdots, u(-m+1)]
$$

Then, we can obtain:

$$
f[u(k), u(k-1), \cdots, u(k-m+1)]=\bar{f}[W, u(k)]
$$

The first order Taylor expansion of function $\bar{f}[W, u(k)]$ near $[W, 0]$ is obtained by using the Taylor theorem:

$$
p_{1}[W, u]=\bar{f}(W, 0)+\left.\frac{\partial \bar{f}}{\partial W}\right|_{(W, 0)} \cdot u(k)
$$

The remainder term is $R[W, u]=\bar{f}(W, u)-p_{1}[W, u]$, and also,

$$
R[W, u] \leq \frac{M_{2} u^{2}}{2}
$$

Where

$$
M_{2}=\max \left\{\frac{\partial^{2}}{\partial u^{2}} \bar{f}[W, u]^{\cdot} W \in K_{W},|u| \leq u_{0}\right\}
$$

Thus the model of cooling control system of casting billet can be approximately written as follows:

$$
y(k+d)=A\left(z^{-1}\right) y(k)+f_{0}[u(k-1), \cdots, u(k-m+1)]+f_{1}[u(k-1), \cdots, u(k-m+1)] u(k)
$$

If only considering the identification problem, the formula (7) is the most accurate. However, to control the system by using the formula 14 can greatly improve the tracking performance. For the cooling control system of casting billet(formula 8$)$. The controller is as follows:

$$
u(k)=g\left[y^{*}(k+d), u(k-1), \cdots, u(k-m+1)\right]
$$

Under the control signal, the system can track the desired output value through the $d t h$ step. If the main function $f_{1}()$ keeps constant positive or negative, the control signal of the object can be 
calculated:

$$
u(k)=\frac{y^{*}(k+d)-f_{0}[u(k-1), \cdots, u(k-m+1)]-A\left(z^{-1}\right) y(k)}{f_{1}[u(k-1), \cdots, u(k-m+1)]}
$$

The approximate model of the system is obtained by Taylor's theorem, and the neural network is trained by the static gradient method. Then the control law is obtained by the linear model.

The steps of the control algorithm are as follows: (1) Calculating the surface temperature of casting billet by using formula 1 and its boundary conditions. (2) Calculating the water setting value of secondary cooling zone by using formula 6. (3) Calculating the cooling water quantity of the surface temperature control system of the casting billet by using formula 16. (4) Adjusting water quantity of secondary cooling section combined with regulating water quantity.

The cooling water quantity obtained by the method is more accurate, and the surface temperature fluctuation of the casting billet is small on the basis of accurate quantity matching. Therefore, the method reduce the number of defective blanks.

\section{Modeling Verification}

In order to verify the model, we do the site test and the verification of the model based on the selection of the $60 \mathrm{Si}^{2} \mathrm{MnA}$ billet of $300 * 360 \mathrm{~mm}$, and use the infrared thermometer to measure the surface temperature on the casting billet at different positions. Compared between calculated values and the measured values. The result is shown in Table1.

Tab.1 Comparison between measured values and calculated values of billet temperature

\begin{tabular}{|c|c|c|c|c|c|c|}
\hline \multirow{2}{*}{$\begin{array}{l}\text { Casting } \\
\text { speed } \\
\mathrm{m} / \mathrm{min}\end{array}$} & \multicolumn{2}{|c|}{$\begin{array}{c}\text { The surface } \\
\text { temperature of } 3.1 \mathrm{~m}\end{array}$} & \multicolumn{2}{|c|}{$\begin{array}{c}\text { The surface } \\
\text { temperature of } \\
5.1 \mathrm{~m} \\
\end{array}$} & \multicolumn{2}{|c|}{$\begin{array}{c}\text { The surface } \\
\text { temperature of } \\
\text { straightening points }\end{array}$} \\
\hline & $\begin{array}{l}\text { Measure } \\
\text { d values }\end{array}$ & $\begin{array}{c}\text { Calculated } \\
\text { values }\end{array}$ & $\begin{array}{l}\text { Measu } \\
\text { red } \\
\text { values } \\
\end{array}$ & $\begin{array}{c}\text { Calculate } \\
\text { d values }\end{array}$ & $\begin{array}{l}\text { Measure } \\
\text { d values }\end{array}$ & $\begin{array}{c}\text { Calculated } \\
\text { values }\end{array}$ \\
\hline 0.5 & & & 945 & 94 & 920 & 917 \\
\hline 0.55 & 990 & 986 & 960 & 956 & 940 & 937 \\
\hline
\end{tabular}

After optimization, the error between the measured values and calculated values is $3.67^{\circ} \mathrm{C}$, in accordance with established requirements. The results show that the solidification and heat transfer model can simulate the solidification process of casting billet and predict eh surface temperature of casting billet. The simulation results of the secondary cooling water distribution by using the are shown in Table 2. The improvement result of quality of casting billet by using the surface temperature control system of casting billet are shown in Fig. 2.

After optimization, the water volume decreased by $1.7 \%$, which achieved the purpose of water saving and energy saving. At the same time, the water distribution is more reasonable, the variation of slab surface temperature fluctuation is reduced, and the purpose of improving slab quality is achieved.

\begin{tabular}{|c|c|c|c|}
\hline \multirow{2}{*}{$\begin{array}{l}\text { Secondary cooling } \\
\text { zone }\end{array}$} & \multicolumn{3}{|c|}{ Water/(L/min) } \\
\hline & Initial & Before & After \\
\hline Secondary cooling & 427 & 623 & 432 \\
\hline Secondary cooling & 369 & 435 & 378 \\
\hline Secondary cooling & 297 & 343 & 324 \\
\hline Secondary cooling & 186 & 219 & 197 \\
\hline Secondary cooling & 121 & 176 & 142 \\
\hline Secondary cooling & 96 & 135 & 114 \\
\hline Total water/L & 1496 & 1931 & 1587 \\
\hline
\end{tabular}




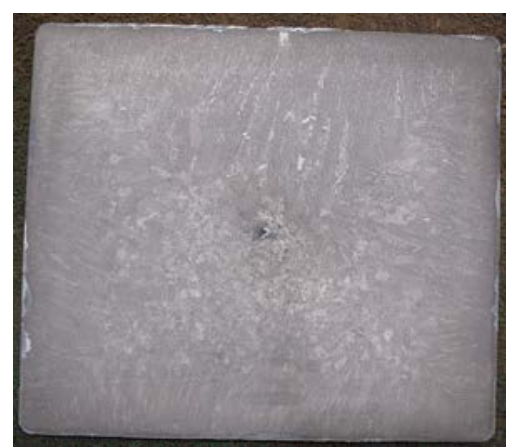

(a) defects picture of casting billet Fig.2 Comparison of quality improvement of casting billet

\section{Conclusion}

On the base of solidification and heat transfer mathematical model, combined with the casting speed and casting temperature, established the secondary cooling water distribution model, constructed a surface temperature control system of casting billet based on neural network control. It can adjust secondary cooling water distribution through the water temperature control system, and make the secondary cooling water distribution process more reasonable, and reduce the slab surface temperature fluctuation, so as to improve the billet quality, reduce the quality defects.

\section{Acknowledgement}

This paper is for project: Research on secondary cooling water distribution model of casting billet (NO.ZD2015041).

\section{Reference}

[1] CHANG Yunhe, ZHANG Jiaquan, et al. Development and application of special shaped billet dynamic secondary cooling control model which based on finite element method[J]. Journal of University of Science and Technology Beijing , 2011, 33(4):418-422.

[2] GAO Wenjiang, GUO Liangliang, et al. The design on secondary cooling of slab continuous casting which based on the mathematical model of transient heat transfer[J]. Metallurgical Equipment, 2014, 209(2):1-4.

[3] ZHANG Jinhong, JIA Junli, ZHANG Shuyan. Metallurgy Continuous Casting and Secondary Cooling Water Distribution Control Considering Uneven Cooling Speed[J]. Bulletin of Science and Technology, 2014, 30(11):55-58.

[4] WANG Haixia, WANG Jun. Study of Spray in Process of Continuous Slab Casting Based on Genetic Algorithm[J]. SURFACE TECHNOLOGY, 2016,45(2):194-198.

[5] REN Tingzhi, LI Yan, MA Caisheng, et al. Research and Development on Solidification Heat Transfer Model of Slab Continuous Casting[J].FOUNDRY TECHNOLOGY, 2016, 37(4):723-728. 